\title{
Frequent DPH3 promoter mutations in skin cancers
}

\author{
Evgeniya Denisova ${ }^{1}$, Barbara Heidenreich ${ }^{1}$, Eduardo Nagore ${ }^{2}$, P. Sivaramakrishna \\ Rachakonda $^{1}$, Ismail Hosen ${ }^{1}$, Ivana Akrap ${ }^{3}$, Víctor Traves ${ }^{4}$, Zaida García-Casado ${ }^{5}$, \\ José Antonio López-Guerrero ${ }^{5}$, Celia Requena ${ }^{2}$, Onofre Sanmartin ${ }^{2}$, Carlos Serra- \\ Guillén², Beatriz Llombart ${ }^{2}$, Carlos Guillén ${ }^{2}$, Jose Ferrando6, Enrique Gimeno ${ }^{6}$, \\ Alfred Nordheim ${ }^{3,7}$, Kari Hemminki, ${ }^{1,8}$ and Rajiv Kumar ${ }^{1}$ \\ ${ }^{1}$ Division of Molecular Genetic Epidemiology, German Cancer Research Center, Heidelberg, Germany \\ 2 Department of Dermatology, Instituto Valenciano de Oncologia, Valencia, Spain \\ ${ }^{3}$ Interfaculty Institute of Cell Biology, Tuebingen University, and IMPRS ("From Molecules to Organisms"), Tuebingen, \\ Germany \\ ${ }^{4}$ Department of Pathology, Instituto Valenciano de Oncologia, Valencia, Spain \\ ${ }^{5}$ Laboratory of Molecular Biology, Instituto Valenciano de Oncologia, Valencia, Spain \\ ${ }^{6}$ Departments of Pathology \& Dermatology, Hospital Arnau de Vilanova, Valencia, Spain \\ ${ }^{7}$ German Cancer Consortium (DKTK/DKFZ) Heidelberg, Germany \\ ${ }^{8}$ Center for Primary Health Care Research, Lund University, Malmö, Sweden \\ Correspondence to: Rajiv Kumar, email: r.kumar@dkfz.de \\ Keywords: DPH3, OXNAD1, whole-exome sequencing, noncoding mutations, skin cancers \\ Received: August 10, $2015 \quad$ Accepted: September 12, $2015 \quad$ Published: September 21, 2015
}

This is an open-access article distributed under the terms of the Creative Commons Attribution License, which permits unrestricted use, distribution, and reproduction in any medium, provided the original author and source are credited.

\section{ABSTRACT}

Recent reports suggested frequent occurrence of cancer associated somatic mutations within regulatory elements of the genome. Based on initial exome sequencing of $\mathbf{2 1}$ melanomas, we report frequent somatic mutations in skin cancers in a bidirectional promoter of diphthamide biosynthesis 3 (DPH3) and oxidoreductase NAD-binding domain containing 1 (OXNAD1) genes. The UV-signature mutations occurred at sites adjacent and within a binding motif for E-twenty six/ternary complex factors (Ets/TCF), at -8 and -9 bp from DPH3 transcription start site. Follow up screening of $\mathbf{5 8 6}$ different skin lesions showed that the DPH3 promoter mutations were present in melanocytic nevi $(2 / 114 ; 2 \%)$, melanoma $(30 / 304 ; 10 \%)$, basal cell carcinoma of skin (BCC; 57/137; 42\%) and squamous cell carcinoma of skin (SCC; $12 / 31 ; 39 \%$ ). Reporter assays carried out in one melanoma cell line for DPH3 and OXNAD1 orientations showed statistically significant increased promoter activity due to $-8 /-9$ CC > TT tandem mutations; although, no effect of the mutations on DPH3 and OXNAD1 transcription in tumors was observed. The results from this study show occurrence of frequent somatic non-coding mutations adjacent to a pre-existing binding site for Ets transcription factors within the directional promoter of DPH3 and OXNAD1 genes in three major skin cancers. The detected mutations displayed typical UV signature; however, the functionality of the mutations remains to be determined.

\section{INTRODUCTION}

Emerging reports have identified frequent somatic mutations within regulatory sequences of the human genome [1-4]. Initially, the only regulatory mutations that are common in many cancers were reported in the core promoter of the telomerase reverse transcriptase (TERT) gene, which increase TERT transcription through creation of binding motifs for E-twenty six/ternary complex (Ets/TCF) transcription factors $[1,2,5,6]$. Recent initiatives directed at genome wide search for noncoding regulatory mutations have uncovered alterations 
upstream of a number of genes [3, 4, 7]. In particular, the non-coding mutations in the succinate dehydrogenase complex, subunit D, integral membrane protein (SDHD) and diphthamide biosynthesis 3 (DPH3) promoters have been shown to affect Ets binding motifs and occurred in melanoma at frequencies of $4-10$ and $13 \%$, respectively [3, $4,8]$. The non-coding mutations add to the complexity of melanoma genome, which is characterized by one of the highest prevalence of somatic mutations [9-18].

In this report we show that typical ultraviolet (UV) signature mutations in the promoter region of $\mathrm{DPH} 3$ and oxidoreductase NAD-binding domain containing 1 (OXNAD1) genes (henceforth, called DPH3 promoter mutations), adjacent and within a preexisting Ets binding site, occur not only in melanoma but are common in basal cell (BCC) and squamous cell (SCC) carcinomas of skin. The mutations in the $D P H 3$ promoter putatively abrogate the pre-existing binding motif for Ets transcription factors, whereas the mutations in TERT promoter result in de novo creation of those motifs.

\section{RESULTS}

Mutations in the DPH3 promoter were initially detected by exome-sequencing of 21 paired DNA from primary tumors and corresponding blood tissues from melanoma patients (Suppl. Table S1). Sequencing reads supporting $\mathrm{C}>\mathrm{T}$ mutations at hg19 coordinate chr3:16,306,504 (8 bp upstream of DPH3 RefSeq transcription start site (TSS) - hence named $-8 \mathrm{C}>\mathrm{T}$ -

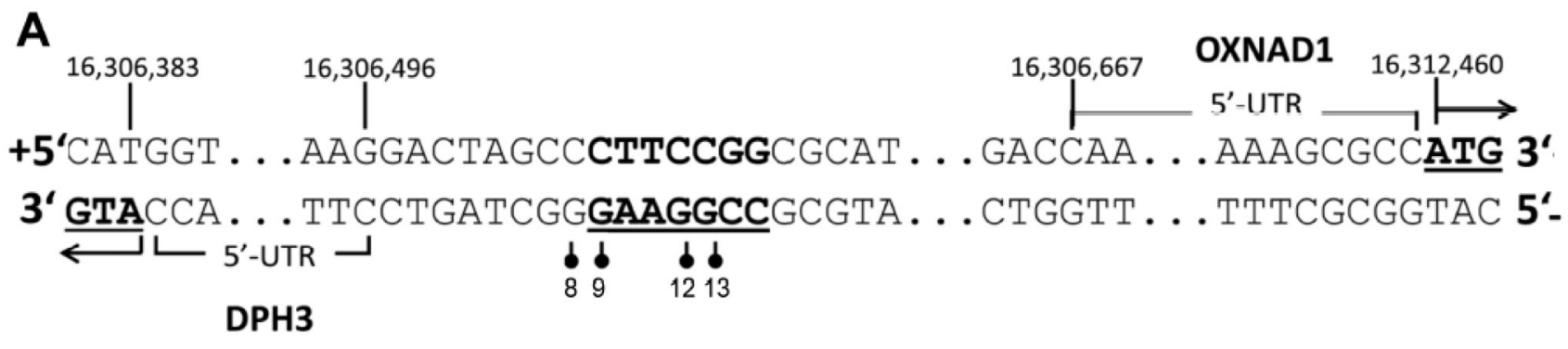

B
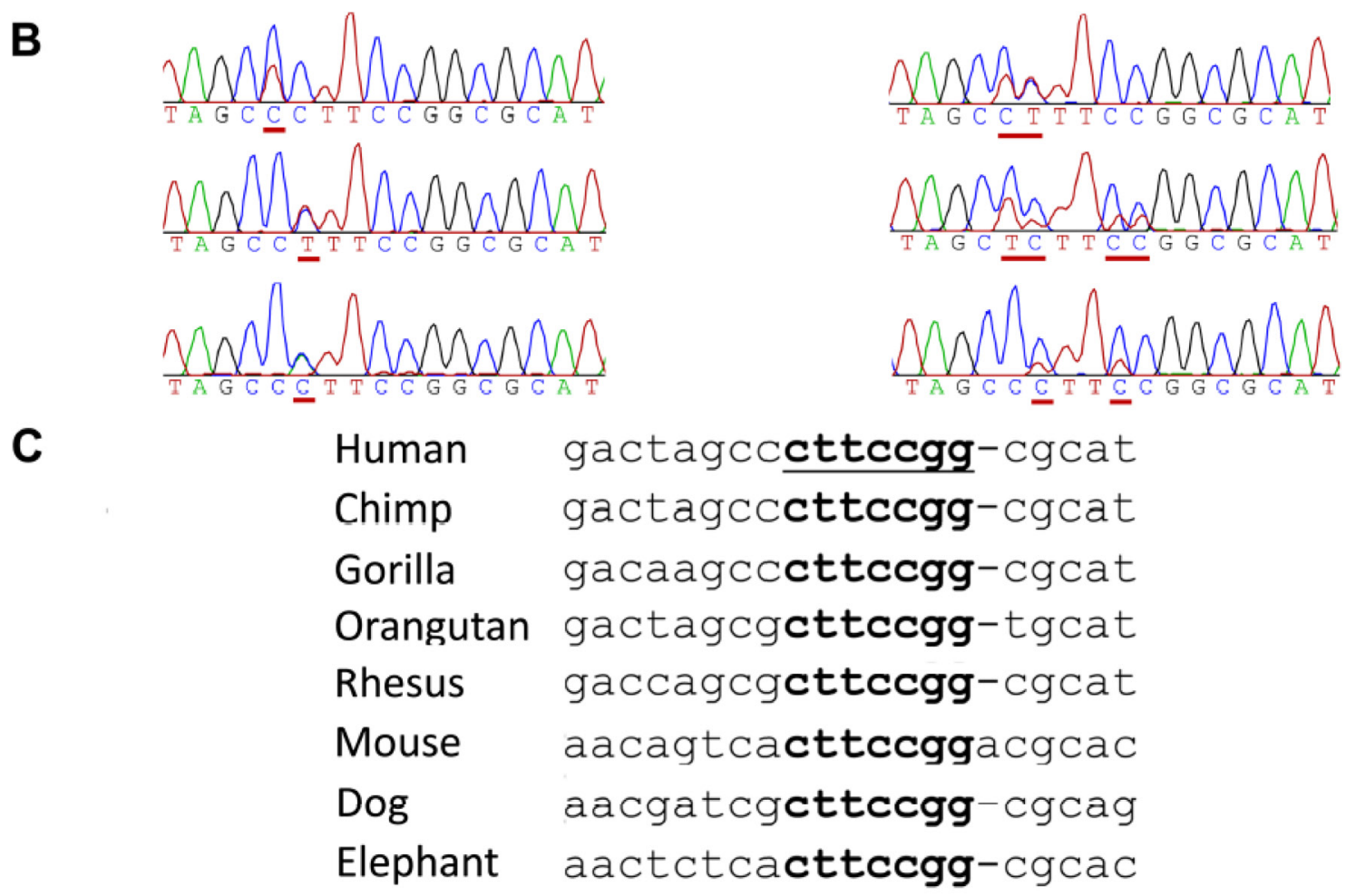

Figure 1: Recurrent somatic mutations in the $\mathrm{DPH} 3$ promoter region. A. The mutated positions (indicated with vertical bars with filled circles) in the promoter region of the $D P H 3$ gene adjacent and within a predicted Ets/TCF binding site, which is shown in bold and underlined. Positions " 8 ", "9", "12" and "13" correspond to the distance from transcription start site (TSS; RefSeq) of DPH3, which is transcribed from negative strand. Those mutated sites correspond to 163, 162, 159 and 158 bp positions from OXNAD1 TSS (RefSeq), respectively, which is transcribed from positive strand in opposite orientation. B. Representative Sanger sequencing chromatograms with mutated positions underlined. C. Multiple alignment of the mutated region from different species (UCSC genome browser, Multiz Alignments of 100 Vertebrates). The positions of mutations at "9", "12" and "13" bp are conserved, the conserved motif is underlined. 


\section{Table 1: Frequency of $D P H 3$ promoter mutations in different cancer types}

\begin{tabular}{|c|c|c|c|}
\hline & $\begin{array}{c}\text { Melanoma } \\
\mathbf{n}=304\end{array}$ & $\begin{array}{c}\text { Basal Cell Carcinoma } \\
n=137^{c}\end{array}$ & $\begin{array}{l}\text { Squamous Cell Carcinoma } \\
\qquad \mathrm{n}=31^{\mathrm{e}}\end{array}$ \\
\hline All mutations & $30(10 \%)$ & $57(42 \%)$ & $12(39 \%)$ \\
\hline$-8 \mathrm{C}>\mathrm{T}$ & $14^{\mathrm{a}}(5 \%)$ & $27(20 \%)$ & $3(9 \%)$ \\
\hline$-9 \mathrm{C}>\mathrm{T}$ & $12^{\mathrm{b}}(4 \%)$ & $13(9 \%)$ & $5(16 \%)$ \\
\hline$-8 /-9 \mathrm{CC}>\mathrm{TT}$ & $2(1 \%)$ & $14^{\mathrm{d}}(10 \%)$ & $3^{f}(10 \%)$ \\
\hline$-9 \mathrm{C}>\mathrm{A}$ & 1 & 2 & 1 \\
\hline$-12 \mathrm{C}>\mathrm{T}$ & 1 & 1 & 0 \\
\hline \multicolumn{4}{|c|}{ 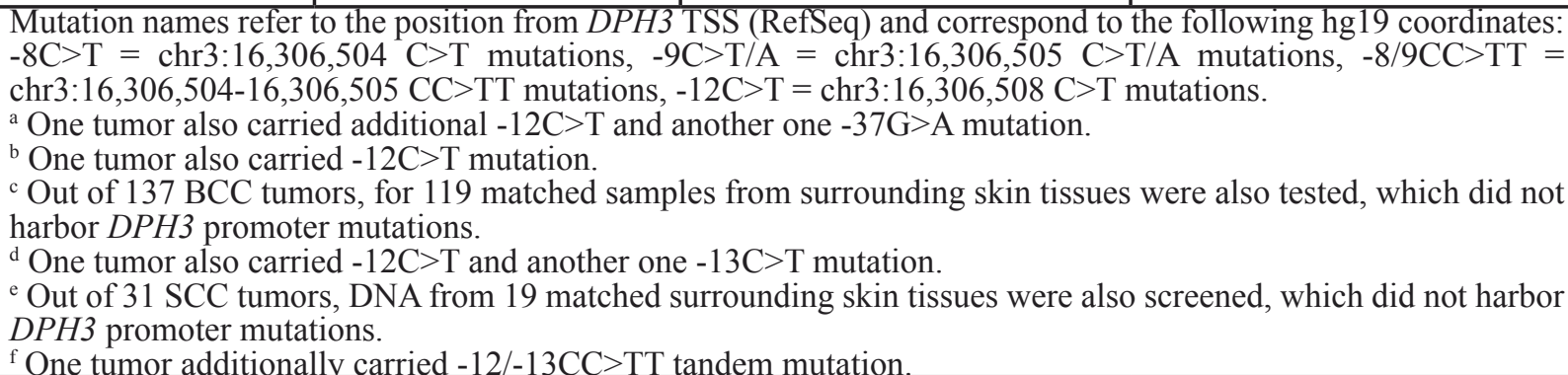 } \\
\hline
\end{tabular}

and 163 bp upstream of OXNAD1 RefSeq TSS) and/or chr3:16,306,505 (9 bp upstream of DPH3 RefSeq TSS hence named $-9 \mathrm{C}>\mathrm{T}$ - and 162 bp upstream of OXNAD1 RefSeq TSS) were discovered in 6 tumors with allelic fraction ranging from 1.4 to $32 \%$ (Suppl. Table S2). One $\mathrm{C}>\mathrm{T}$ mutation at $-9 \mathrm{bp}$ position and one $\mathrm{CC}>\mathrm{TT}$ tandem mutation at $-8 /-9$ bp positions with allelic fractions of $32 \%$ and $20 \%$, respectively, were confirmed by Sanger sequencing (Suppl. Figure S1).

Follow up sequencing of 304 melanomas showed that those mutations, lying within and adjacent to a preexisting Ets/TCF binding motif CCTTCCGG (CCGGAAGG on the reverse strand were present in 30 $(10 \%)$ tumors (Table 1; Figure 1A, 1B).

The most recurrent mutations were $\mathrm{C}>\mathrm{T}$ transitions at $-8(14 ; 5 \%)$ and -9 bp $(12 ; 4 \%)$ followed by $-8 /-9 \mathrm{CC}>$ TT tandem mutations (2; $1 \%$; Figure 1B). Other mutations included one $\mathrm{C}>\mathrm{A}$ transversion at -9 bp and one $\mathrm{C}>$ $\mathrm{T}$ transition at $-12 \mathrm{bp}$. The $\mathrm{C}>\mathrm{T}$ mutation at $-12 \mathrm{bp}$ in two melanomas co-occurred with $-8 \mathrm{C}>\mathrm{T}$ and $-9 \mathrm{C}>\mathrm{T}$ mutations, respectively (Table 1 ). The $D P H 3$ promoter mutations were also detected in two (one $-8 \mathrm{C}>\mathrm{T}$ and one $-9 \mathrm{C}>\mathrm{T}$ ) of the 114 melanocytic nevi. In addition the screening showed that the mutations were present in 57 of $137(42 \%)$ BCC and in 12 out of $31(39 \%)$ SCC (Table 1). We also screened DNA from skin tissues surrounding tumors from $119 \mathrm{BCC}$ and 19 SCC patients and did not detect any $D P H 3$ promoter mutations.

Given the reported rate of mutations in melanoma, $\mathrm{BCC}$ and SCC, the frequencies of $\mathrm{C}>\mathrm{T}$ base changes at $-8 \mathrm{bp}$ and $-9 \mathrm{bp}$ positions were statistically significantly higher than expected by chance $\left(P<2.2 \times 10^{-16}\right.$ for each position in melanoma and $\mathrm{BCC}$, binomial test; $P=1.7 \times 10^{-}$ ${ }^{10}$ and $P<2.2 \times 10^{-16}$ for $-8 \mathrm{C}>\mathrm{T}$ and $-9 \mathrm{C}>\mathrm{T}$, respectively, in SCC). The mutations in the $\mathrm{DPH} 3$ promoter tend to cooccur with TERT promoter mutations more frequently than expected by chance in melanoma $(\mathrm{OR}=3.0,95 \% \mathrm{CI} 1.4$ - 6.4, $P=0.006), \mathrm{BCC}(\mathrm{OR}=3.4,95 \%$ CI $1.5-7.6, P=$ $0.003)$ and $\mathrm{SCC}(\mathrm{OR}=4.3,95 \% \mathrm{CI} 0.9-20.2, P=0.06$; Figure 2). We also screened DNA from bladder tumors ( $n$ $=70)$, gliomas $(n=70)$ and squamous cell carcinoma of esophagus $(n=22)$ and none harbored $D P H 3$ promoter alterations.

The sites of two main mutations $(-8 \mathrm{C}>\mathrm{T}$ and $-9 \mathrm{C}>\mathrm{T}$ ) were adjacent to the core binding motif 5'TTCCGG (5'CCGGAA on the reverse strand) for Ets/ TCF transcription factors $[1,19]$. Transcription factor binding site search of the mutated region using different algorithms resulted in identification of Ets/TCF proteins ELK1 and ELK4 sites with highest score. The mutational sites also overlapped with chromatin immunoprecipitation sequencing peaks for various transcription factors (ENCODE data), including the Ets family members ELK1, ELK4, ELF1 and GABPA (Suppl. Figure S2) [20]. The motif containing the mutations, with exception of the -8 position, is highly conserved across the mammalian lineage (Figure 1C; data from UCSC genome bowser [21]).

In Luciferase reporter assays carried out in two orientations, for $D P H 3$ and $O X N A D 1$, the promoter activity due to constructs with the $-8 /-9 \mathrm{CC}>\mathrm{TT}$ tandem mutation was statistically significantly higher than the constructs with wild type sequence $(P=0.03$ DPH3; $P=0.001$ OXNAD1). The constructs with the tandem mutation showed 1.24 and 1.44 fold higher promoter activity than the constructs with wild type sequence for $D P H 3$ and $O X N A D 1$, respectively. The activity due to the promoter constructs with the $-8 \mathrm{C}>\mathrm{T}$ and $-9 \mathrm{C}$ 
$>\mathrm{T}$ mutations was, though higher than the wild type constructs in both $D P H 3$ and $O X N A D 1$ orientations, but the differences were not statistically significant (Figure 3). We did not observe a statistically significant difference in the DPH3 transcription levels based on the mutational status of the $D P H 3$ promoter in melanoma, melanocytic nevi and BCC tumors. In 20 tumors from SCC patients, seven with mutations and 13 without mutations, the DPH3 transcription was lower in tumors with mutations than those without (Suppl. Figure S3). We also did not observe any effect of mutations on the transcription levels of OXNAD1 gene in BCC (Suppl. Figure S4).

The analysis of the mutational data showed that in melanoma the $\mathrm{DPH} 3$ promoter mutations associated with presence of solar lentigines at tumor sites. In BCC, DHP3 promoter mutations associated with increased occupational sun exposure and personal history of nonmelanoma skin cancers (Suppl. Table S3).

\section{DISCUSSION}

In this communication we report frequent somatic mutations within a bidirectional promoter region of $D P H 3$ and $O X N A D 1$ genes in three major types of skin cancers. The initial discovery of the non-coding mutations within DPH3 promoter through exome sequencing followed by a screening of 586 different skin cancer lesions showed that those promoter mutations occurred not only in 10 percent of melanoma but were also present at a frequencies of 42 percent in BCC and 39 percent in SCC. The mutations were characterized by specificity, recurrence and depicted typical UV signature as all the alterations resulted in $\mathrm{C}$ to $\mathrm{T}$ transitions at dipyrimidine sites, which was further augmented by 25 percent of all alterations in BCC and in SCC being CC $>$ TT tandem mutations [22]. The overall frequency of the $\mathrm{DPH} 3$ promoter mutations approximated that of most frequent alterations in BCC and SCC [23-25]. After TERT promoter mutations, this report constitutes only a second instance of highly frequent mutations being reported in human cancers within the non-coding regulatory sequences that have been called as the 'dark matter' of the genome [26]. However, unlike TERT promoter mutations, the $D P H 3$ promoter mutations were also present in 2 of 114 melanocytic nevi. While TERT promoter mutations are frequent in many cancers, we did not observe the DPH3 mutations in three non-skin cancers that were screened in this study. Aged sun exposed normal skin has been shown to contain clones with various cancer associated mutations; however, in our study we could detect $D P H 3$ promoter mutations unambiguously in tumors but not in the surrounding skin [29].

Whether the detected $D P H 3$ promoter mutations affect transcription of adjacent genes or act as enhancers/ repressors of some distant genes remains to be determined

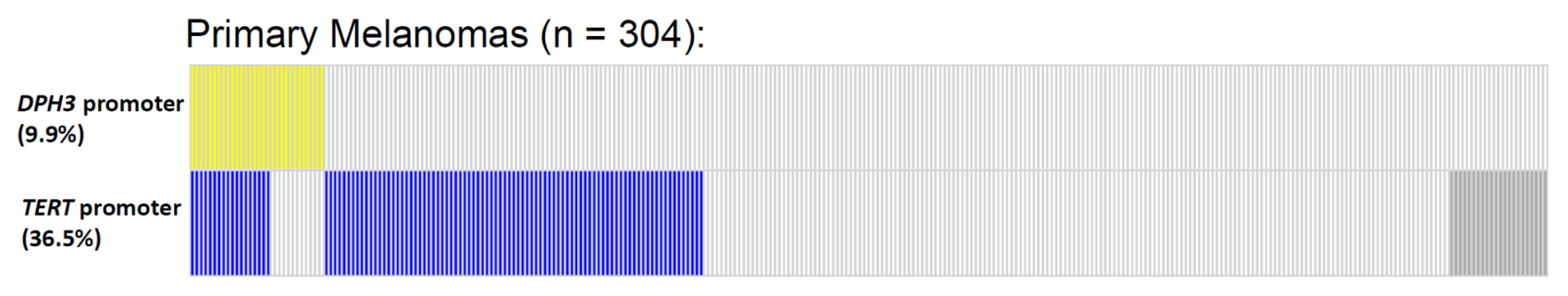

Basal Cell Carcinomas $(n=137)$ :

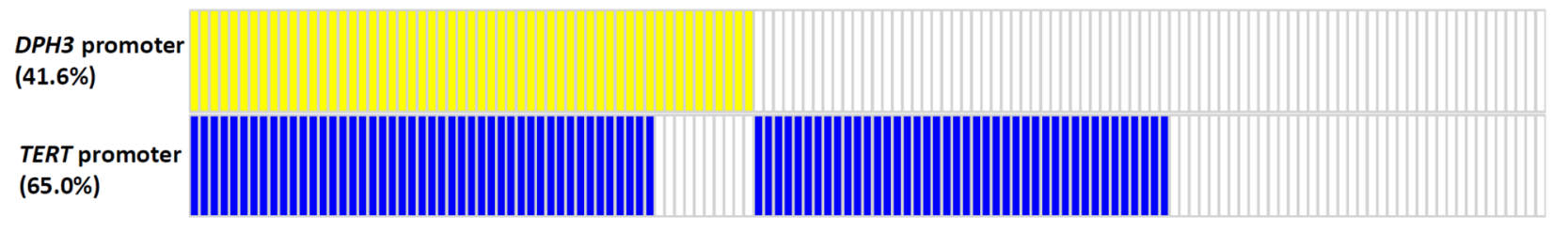

\section{Squamous Cell Carcinomas $(n=31)$ :}

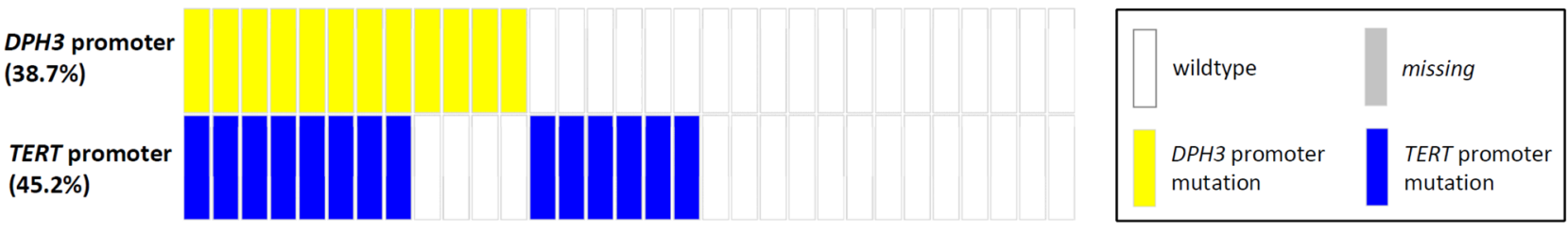

Figure 2: Distribution of mutations in the TERT and DPH3 promoter in primary melanomas, BCCs and SCCs. The mutations at the two loci occurred together more frequently than per chance with an OR of 3.0 for melanoma $(95 \% \mathrm{CI} 1.4-6.4, P=0.006)$, OR of 3.4 for BCC $(95 \%$ CI $1.5-7.6, P=0.003)$ and OR of 4.3 for SCC $(95 \%$ CI $0.9-20.2, P=0.06)$. Two-sided $P$ values and relative risk were determined by $\mathrm{chi}^{2}$ test. 
[7]. However, it may be pointed out that over-expression of Dph3 promotes the migratory ability of murine melanoma cells, whereas down regulation of Dph3 expression inhibited cellular invasion and metastasis in vivo [27]. The creation of Dph3 knock-out mice revealed that loss of both dph3 alleles causes a general delay in embryonic development and is embryonically lethal [28]. DPH3 encodes a short peptide involved in electron transfer during the synthesis of eukaryotic diphthamide and forms a complex with Kti13 which is involved in both tRNA and translational elongation factor 2 (EF2) modifications $[30,31]$. Diphthamide is a modified histidine residue of archaeal and eukaryotic EF2 that helps in maintenance of translational fidelity and is itself a target of translational inhibitors, diphtheria toxin and Pseudomonas exotoxin A $[32,33]$.
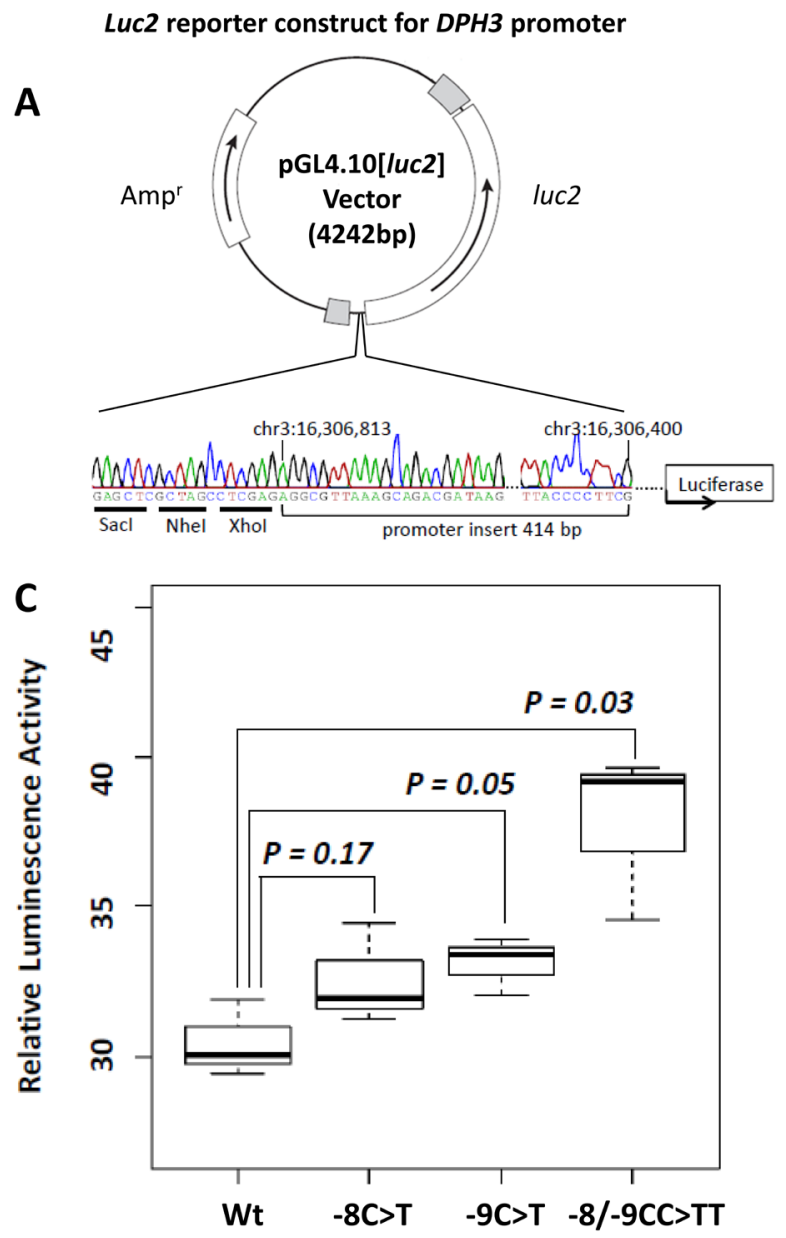

The mutations in the $D P H 3$ promoter were first reported in melanoma in a study based on genome wide search for mutations in the regulatory regions of the genome. The reported frequency of $D P H 3$ mutations in melanoma from whole genome and exome sequencing data in the Cancer Genome Atlas (TCGA) approximated $16 \%(6 / 38)$ and $14 \%(25 / 176)$, respectively [4]. The sequence element with most frequent mutations was in proximity to Ets/TCF binding motif and earlier report suggested that the immediate adjacent frequently mutated nucleotide ( -9 bp position) forms the part of ELF1 binding motif [3]. Members of the Ets transcription factor family are known to act as activators as well as repressors of transcription [34-36]. In the case of the DPH3 promoter the question of contributing transcription factors and the effect of the mutations remain elusive.
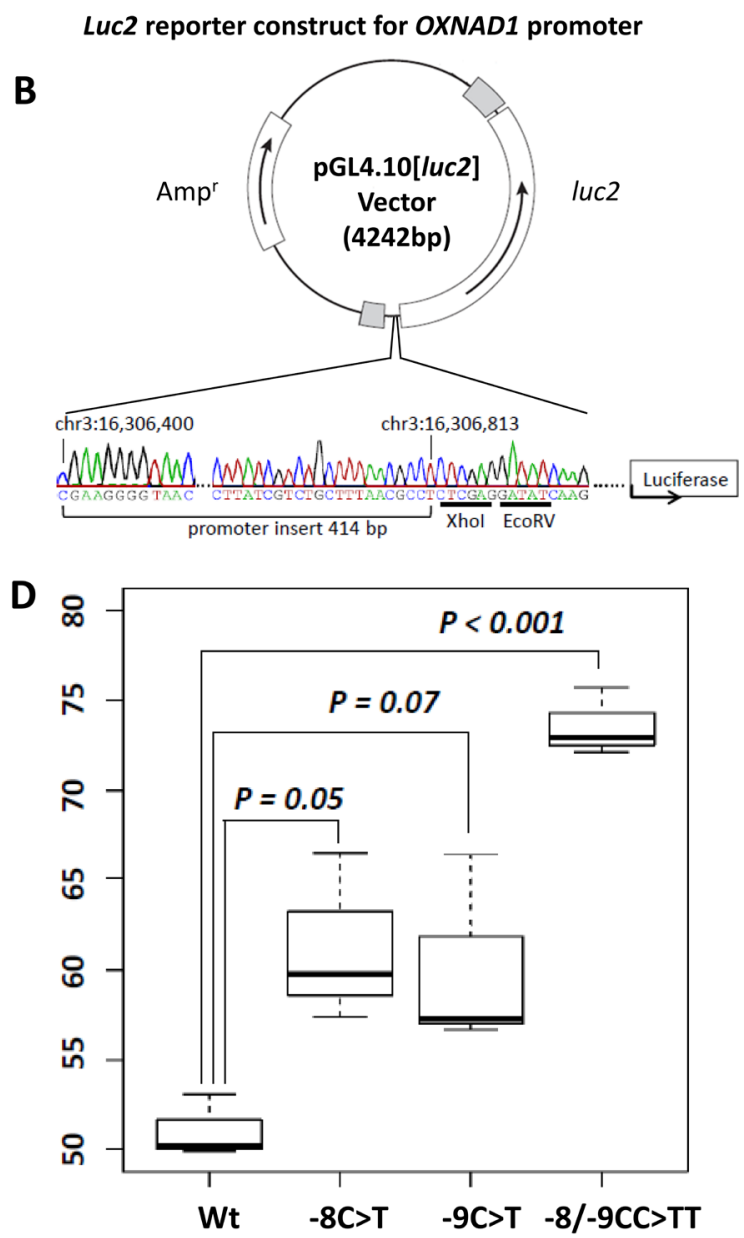

Figure 3: Luciferase reporter assays for the bidirectional promoter region. A.-B. Luciferase reporter constructs for $D P H 3$ and OXNAD1. Promoter insert (chr3: 16,306,400-16,306,813, hg19 coordinates) was subcloned into pGL4.10[luc2] vector in two orientations: for $D P H 3$ A. transcribed from "." strand and for OXNAD1 B. transcribed from "+" strand. The correctness of insert orientations were confirmed by Sanger sequencing. The positive strand (containing luc2 ATG) sequence is shown for both constructs, which corresponds to the genomic DNA positive strand for $O X N A D 1$ insert and negative strand in reverse orientation for $D P H 3$ insert. The restriction sites in the vectors are underlined. C.-D. Relative luciferase activity due to different promoter constructs. DPH3 C. and OXNAD1 D. promoter constructs without mutations (Wt), with $-8 \mathrm{C}>\mathrm{T}$, $-9 \mathrm{C}>\mathrm{T}$ and $-8 /-9 \mathrm{CC}>\mathrm{TT}$ mutations were transfected into UKRV-Mel-21 melanoma cells. The reporter activity due to the inserts with the tandem $-8 /-9 \mathrm{CC}>\mathrm{TT}$ mutation was 1.24 and 1.44 fold higher than with wild type sequence inserts for DPH3 and OXNAD1, respectively. The reporter activity in cells transfected with constructs with $-8 \mathrm{C}>\mathrm{T}$ or $-9 \mathrm{C}>\mathrm{T}$ mutations was higher than the wild type constructs but the differences were not statistically significant. 
Although the luciferase reporter constructs with the $-8 /-9 C C>$ TT tandem mutation showed statistically significant increased promoter activity for both $D P H 3$ and $O X N A D 1$ orientations in a melanoma cell line, we did not detect a statistically significant difference in the $D P H 3$ and $O X N A D 1$ transcription levels in melanomas and basal cell carcinomas. The expression of DHP3 was lower in SCC tumors with mutations than those without; however, the number of tumors investigated was limited. A plausible explanation for the observed increase in promoter activity and no effect on transcription could be due to fact that the mutations alter transient transcriptional responses or temporal patterns during cell cycle progression that are not readily detectable at the whole-tumor level as discussed earlier [4].

Our study remains limited due to undetermined functionality of the mutations. However, the specificity and high recurrence of the mutations in the $\mathrm{DPH} 3$ promoter, particularly in BCC and SCC and findings from an earlier report in melanoma, merits further investigations for determining the functionality and relevance of those mutations in the process of carcinogenesis [4].

\section{MATERIALS AND METHODS}

\section{Patient samples}

Primary tumors and corresponding blood samples from 21 melanoma patients for exome sequencing (Suppl. Table S1) and for follow up validation primary tumors from 304 melanoma patients, tumors and surrounding tissues from 137 skin BCC and 31 skin SCC patients (Suppl. Table S3) and 114 melanocytic nevi included in this study were retrieved from the biobank of the Instituto Valenciano de Oncologia in Valencia, Spain. Of 114 melanocytic nevi, 16 were obtained from melanoma patients and 98 were from healthy individuals and of those 16 reported a family history of melanoma. Melanoma patients included in the study were classified according TNM staging system (based on the extent of the tumor (T), the extent of spread to the lymph nodes $(\mathrm{N})$, and the presence of metastasis (M)) of the American Joint Committee on Cancer (AJCC) [37]. All BCC tumors were localized and did not include locally advanced tumors; SCC tumors were also localized without nodal or distant metastasis. Histological examination of the nevi included in the study showed that 11 were atypical, 84 compound, 4 congenital, 12 intradermal and 1 junctional. The nevi that carried DPH3 promoter mutations were compound and originated from individuals that did not have personal or family history of melanoma.

Ethical approval for the study from the institutional review board of the Instituto Valenciano de Oncologia and written informed consent from all study patients were obtained. DNA samples from 70 tumors from urothelial bladder cancer patients, 70 gliomas, and 22 tumors from patients with squamous cell carcinoma of esophagus were retrieved from the departmental collection described previously in various studies [38-40].

\section{Exome capture and Illumina sequencing}

Exome capture was performed using Agilent SureSelect Target Enrichment System, Human All Exon V5+UTRs kit (Agilent Technologies) according to standard protocol. Capture area comprised 286754 targets from 21522 genes including untranslated regions $(\sim 75 \mathrm{Mb}$ in total).

Sequencing of 21 tumor/normal pairs was carried out on Illumina Hiseq2000 with paired-end 101-nucleotide reads using protocol provided by the manufacturer. Coverage statistics was generated by Flagstat and DepthOfCoverage functions from Genome Analysis Toolkit (GATK) version 3.1-1 for the capture regions with $50 \mathrm{bp}$ padding [41]. The average coverage of x68 and x64 was obtained for DNA from tumor and blood tissues, respectively (Suppl. Table S4) .

\section{Read mapping and data preprocessing}

Read pairs were mapped to the human reference genome (build hg19) using Burrows-Wheeler Aligner (BWA) version 0.7.5a mem function with default parameters [42]. BAM files were coordinate-sorted and duplicates were removed by Picard software version 1.102 (see URLs). Base quality score recalibration and local realignment around indels were performed by GATK prior to variant calling. Additional round of local realignment was performed jointly for tumor/normal pairs to avoid alignment differences in samples from one patient as suggested by GATK "best practices". All preprocessing steps were performed for the capture regions with $50 \mathrm{bp}$ padding.

\section{Identification of somatic single nucleotide variations (SSNVs)}

Capture regions with $50 \mathrm{bp}$ padding were used for variant calling to include flanking noncoding regions. Somatic single nucleotide variants were detected by Mutect algorithm [43]. The minimum base quality of 30 was required. Candidates with at least one highquality base supporting alternate allele in the patientmatched normal sample were excluded. The $\mathrm{C}>\mathrm{T}$ mutation at 16,306,505 was called in 2 samples (MEL11 and MEL12). Manual reviewing of the region using Integrative Genomics Viewer showed that sequencing reads supporting $\mathrm{C}>\mathrm{T}$ mutations at 16,306,505 and/or 
$16,306,504$ positions were present in 6 samples and out of those two samples had tandem $\mathrm{CC}>\mathrm{TT}$ mutation (Suppl. Table S2) [44]. Mutect output examination revealed that the $\mathrm{C}>\mathrm{T}$ mutation at 16,306,505 was originally detected in 4 samples but was filtered out in two because of the low allele frequency ("fstar_tumor_lod, possible_contamination" failure reason). The mutation at $16,306,504$ was initially detected in two samples but was also filtered out.

Variant annotation was performed by ANNOVAR using RefSeq genes annotations, dbSNP (Build ID: 137, see URLs), variants from 1000 Genomes project and Catalogue of Somatic Mutations (COSMIC) version 67 $[45,46]$.

\section{Measurement of DPH3 and OXNAD1 gene expression by quantitative real-time PCR}

For measurement of $D P H 3$ and $O X N A D 1$ expression, reverse transcription reaction was performed using $1 \mu \mathrm{g}$ of RNA and oligo-dT primers using a cDNA synthesis kit (Thermo Scientific, Waltham, USA). DPH3 and $O X N A D 1$ expression levels were then determined by quantitative real-time PCR using a Syber Green kit (QIAGEN). The real-time PCR was carried out in triplicates in 384-well layouts using QuantiTect primers (QIAGEN) specific for DPH3 (QT00223083), OXNAD1 (QT00074235) and the GUSB (QT00046046), a housekeeping gene used as an internal standard. $D P H 3$ and $O X N A D 1$ expression levels were calculated using $G U S B$ expression as a reference and relative quantification was performed using the $\Delta \Delta \mathrm{CT}$ method and $\log 2$ transformation. The expression levels were plotted using box plots and statistical differences were determined using two sided t-tests.

\section{URLs}

Burrows-Wheeler Aligner (BWA), http://bio-bwa. sourceforge.net/; Genome Analysis Toolkit (GATK), http://www.broadinstitute.org/gatk/; Picard, http:// broadinstitute.github.io/picard/; MuTect, http://www. broadinstitute.org/cancer/cga/mutect;ANNOVAR, http:// www.openbioinformatics.org/annovar/; dbSNP, http:// www.ncbi.nlm.nih.gov/SNP/; COSMIC, http://cancer. sanger.ac.uk/cancergenome/projects/cosmic/; Integrative Genomics Viewer (IGV), http://www.broadinstitute.org/ igv/; R, http://www.R-project.org/.

\section{FUNDINGS}

The study was supported by the EU Transcan programs through German Ministry of Education and Science (01KT1511 and 01KT1402).

\section{CONFLICTS OF INTEREST}

The authors declare no competing financial interests.

\section{REFERENCES}

1. Horn S, Figl A, Rachakonda PS, Fischer C, Sucker A, Gast A, Kadel S, Moll I, Nagore E, Hemminki K, Schadendorf $\mathrm{D}$ and Kumar R. TERT promoter mutations in familial and sporadic melanoma. Science. 2013; 339:959-961.

2. Huang FW, Hodis E, Xu MJ, Kryukov GV, Chin L and Garraway LA. Highly recurrent TERT promoter mutations in human melanoma. Science. 2013; 339:957-959.

3. Weinhold N, Jacobsen A, Schultz N, Sander C and Lee W. Genome-wide analysis of noncoding regulatory mutations in cancer. Nat Genet. 2014; 46:1160-1165.

4. Fredriksson NJ, Ny L, Nilsson JA and Larsson E. Systematic analysis of noncoding somatic mutations and gene expression alterations across 14 tumor types. Nat Genet. 2014; 46:1258-1263.

5. Killela PJ, Reitman ZJ, Jiao Y, Bettegowda C, Agrawal N, Diaz LA, Jr., Friedman AH, Friedman H, Gallia GL, Giovanella BC, Grollman AP, He TC, He Y, Hruban RH, Jallo GI, Mandahl N, et al. TERT promoter mutations occur frequently in gliomas and a subset of tumors derived from cells with low rates of self-renewal. Proc Natl Acad Sci U S A. 2013;110:6021-6.

6. Heidenreich B, Rachakonda PS, Hemminki K and Kumar R. TERT promoter mutations in cancer development. Current Opinions in Genetics \& Development. 2014; 24:30-37.

7. Mansour MR, Abraham BJ, Anders L, Berezovskaya A, Gutierrez A, Durbin AD, Etchin J, Lawton L, Sallan SE, Silverman LB, Loh ML, Hunger SP, Sanda T, Young RA and Look AT. Oncogene regulation. An oncogenic superenhancer formed through somatic mutation of a noncoding intergenic element. Science. 2014; 346:1373-1377.

8. Scholz SL, Horn S, Murali R, Moller I, Sucker A, Sondermann W, Stiller M, Schilling B, Livingstone E, Zimmer L, Reis H, Metz CH, Zeschnigk M, Paschen A, Steuhl KP, Schadendorf D, et al. Analysis of SDHD promoter mutations in various types of melanoma. Oncotarget. 2015 Jul 27. [Epub ahead of print] PMID: 26327518 .

9. Alexandrov LB, Nik-Zainal S, Wedge DC, Aparicio SA, Behjati S, Biankin AV, Bignell GR, Bolli N, Borg A, Borresen-Dale AL, Boyault S, Burkhardt B, Butler AP, Caldas C, Davies HR, Desmedt C, et al. Signatures of mutational processes in human cancer. Nature. 2013; 500:415-421.

10. Hodis E, Watson IR, Kryukov GV, Arold ST, Imielinski M, Theurillat JP, Nickerson E, Auclair D, Li L, Place C, Dicara D, Ramos AH, Lawrence MS, Cibulskis K, Sivachenko A, Voet $\mathrm{D}$, et al. A landscape of driver mutations in melanoma. Cell. 2012; 150:251-263. 
11. Krauthammer M, Kong Y, Ha BH, Evans P, Bacchiocchi A, McCusker JP, Cheng E, Davis MJ, Goh G, Choi M, Ariyan S, Narayan D, Dutton-Regester K, Capatana A, Holman EC, Bosenberg M, et al. Exome sequencing identifies recurrent somatic RAC1 mutations in melanoma. Nat Genet. 2012; 44:1006-1014.

12. Berger MF, Hodis E, Heffernan TP, Deribe YL, Lawrence MS, Protopopov A, Ivanova E, Watson IR, Nickerson E, Ghosh P, Zhang H, Zeid R, Ren X, Cibulskis K, Sivachenko AY, Wagle N, et al. Melanoma genome sequencing reveals frequent PREX2 mutations. Nature. 2012; 485:502-506.

13. Gartner JJ, Parker SC, Prickett TD, Dutton-Regester K, Stitzel ML, Lin JC, Davis S, Simhadri VL, Jha S, Katagiri N, Gotea V, Teer JK, Wei X, Morken MA, Bhanot UK, Program NCS, et al. Whole-genome sequencing identifies a recurrent functional synonymous mutation in melanoma. Proc Natl Acad Sci U S A. 2013; 110:13481-13486.

14. Wei X, Walia V, Lin JC, Teer JK, Prickett TD, Gartner J, Davis S, Stemke-Hale K, Davies MA, Gershenwald JE, Robinson W, Robinson S, Rosenberg SA and Samuels Y. Exome sequencing identifies GRIN2A as frequently mutated in melanoma. Nat Genet. 2011; 43:442-446.

15. Aydin IT, Melamed RD, Adams SJ, Castillo-Martin M, Demir A, Bryk D, Brunner G, Cordon-Cardo C, Osman I, Rabadan R and Celebi JT. FBXW7 mutations in melanoma and a new therapeutic paradigm. J Natl Cancer Inst. 2014; 106:dju107.

16. Stark MS, Woods SL, Gartside MG, Bonazzi VF, DuttonRegester K, Aoude LG, Chow D, Sereduk C, Niemi NM, Tang N, Ellis JJ, Reid J, Zismann V, Tyagi S, Muzny D, Newsham I, et al. Frequent somatic mutations in MAP3K5 and MAP3K9 in metastatic melanoma identified by exome sequencing. Nature genetics. 2012; 44:165-169.

17. Nikolaev SI, Rimoldi D, Iseli C, Valsesia A, Robyr D, Gehrig C, Harshman K, Guipponi M, Bukach O, Zoete V, Michielin O, Muehlethaler K, Speiser D, Beckmann JS, Xenarios I, Halazonetis TD, et al. Exome sequencing identifies recurrent somatic MAP2K1 and MAP2K2 mutations in melanoma. Nat Genet. 2012; 44:133-139.

18. The Cancer Genome Atlas Genomic Classification of Cutaneous Melanoma. Cell. 2015; 161:1681-1696.

19. Hollenhorst PC, McIntosh LP and Graves BJ. Genomic and biochemical insights into the specificity of ETS transcription factors. Annu Rev Biochem. 2011; 80:437471.

20. ENCODE project consortium An integrated encyclopedia of DNA elements in the human genome. Nature. 2012; 489:57-74.

21. Kent WJ, Sugnet CW, Furey TS, Roskin KM, Pringle TH, Zahler AM and Haussler D. The human genome browser at UCSC. Genome Res. 2002; 12:996-1006.

22. Premi S, Wallisch S, Mano CM, Weiner AB, Bacchiocchi A, Wakamatsu K, Bechara EJ, Halaban R, Douki T and Brash DE. Photochemistry. Chemiexcitation of melanin derivatives induces DNA photoproducts long after UV exposure. Science. 2015; 347:842-847.

23. Jayaraman SS, Rayhan DJ, Hazany S and Kolodney MS. Mutational landscape of basal cell carcinomas by wholeexome sequencing. J Invest Dermatol. 2014; 134:213-220.

24. South AP, Purdie KJ, Watt SA, Haldenby S, den Breems NY, Dimon M, Arron ST, Kluk MJ, Aster JC, McHugh A, Xue DJ, Dayal JH, Robinson KS, Rizvi SM, Proby CM, Harwood CA, et al. NOTCH1 mutations occur early during cutaneous squamous cell carcinogenesis. J Invest Dermatol. 2014; 134:2630-2638.

25. Durinck S, Ho C, Wang NJ, Liao W, Jakkula LR, Collisson EA, Pons J, Chan SW, Lam ET, Chu C, Park K, Hong SW, Hur JS, Huh N, Neuhaus IM, Yu SS, et al. Temporal dissection of tumorigenesis in primary cancers. Cancer discovery. 2011; 1:137-143.

26. Vogelstein B, Papadopoulos N, Velculescu VE, Zhou S, Diaz LA, Jr. and Kinzler KW. Cancer genome landscapes. Science. 2013; 339:1546-1558.

27. Wang L, Shi Y, Ju P, Liu R, Yeo SP, Xia Y, Owlanj H and Feng Z. Silencing of diphthamide synthesis 3 (Dph3) reduces metastasis of murine melanoma. PLoS One. 2012; 7:e49988.

28. Liu S, Wiggins JF, Sreenath T, Kulkarni AB, Ward JM and Leppla SH. Dph3, a small protein required for diphthamide biosynthesis, is essential in mouse development. Mol Cell Biol. 2006; 26:3835-3841.

29. Martincorena I, Roshan A, Gerstung M, Ellis P, Van Loo P, McLaren S, Wedge DC, Fullam A, Alexandrov LB, Tubio JM, Stebbings L, Menzies A, Widaa S, Stratton MR, Jones PH and Campbell PJ. Tumor evolution. High burden and pervasive positive selection of somatic mutations in normal human skin. Science. 2015; 348:880-886.

30. Dong M, Su X, Dzikovski B, Dando EE, Zhu X, Du J, Freed $\mathrm{JH}$ and Lin H. Dph3 is an electron donor for Dph1-Dph2 in the first step of eukaryotic diphthamide biosynthesis. J Am Chem Soc. 2014; 136:1754-1757.

31. Glatt S, Zabel R, Vonkova I, Kumar A, Netz DJ, Pierik AJ, Rybin V, Lill R, Gavin AC, Balbach J, Breunig $\mathrm{KD}$ and Muller $\mathrm{CW}$. heterodimer and its double role in modificationsStructure of the Kti11/Kti13 of tRNA and eukaryotic elongation factor 2. Structure. 2015; 23:149-160.

32. Abdel-Fattah W, Scheidt V, Uthman S, Stark MJ and Schaffrath R. Insights into diphthamide, key diphtheria toxin effector. Toxins. 2013; 5:958-968.

33. Liu S, Bachran C, Gupta P, Miller-Randolph S, Wang H, Crown D, Zhang Y, Wein AN, Singh R, Fattah R and Leppla SH. Diphthamide modification on eukaryotic elongation factor 2 is needed to assure fidelity of mRNA translation and mouse development. Proceedings of the National Academy of Sciences of the United States of America. 2012; 109:13817-13822.

34. Yang SH and Sharrocks AD. SUMO promotes HDACmediated transcriptional repression. Mol Cell. 2004; 
$13: 611-617$

35. Lee SM, Vasishtha M and Prywes R. Activation and repression of cellular immediate early genes by serum response factor cofactors. J Biol Chem. 2010; 285:2203622049.

36. Buchwalter G, Gross C and Wasylyk B. Ets ternary complex transcription factors. Gene. 2004; 324:1-14.

37. Balch CM, Gershenwald JE, Soong SJ, Thompson JF, Atkins MB, Byrd DR, Buzaid AC, Cochran AJ, Coit DG, Ding S, Eggermont AM, Flaherty KT, Gimotty PA, Kirkwood JM, McMasters KM, Mihm MC, Jr., et al. Final version of 2009 AJCC melanoma staging and classification. J Clin Oncol. 2009; 27:6199-6206.

38. Heidenreich B, Rachakonda PS, Hosen I, Volz F, Hemminki $\mathrm{K}$, Weyerbrock A and Kumar R. TERT promoter mutations and telomere length in adult malignant gliomas and recurrences. Oncotarget. 2015;6:10617-33.

39. Smeds J, Berggren P, Ma X, Xu Z, Hemminki K and Kumar R. Genetic status of cell cycle regulators in squamous cell carcinoma of the oesophagus: the CDKN2A (p16(INK4a) and p14(ARF) ) and p53 genes are major targets for inactivation. Carcinogenesis. 2002; 23:645-655.

40. Rachakonda PS, Hosen I, de Verdier PJ, Fallah M, Heidenreich B, Ryk C, Wiklund NP, Steineck G, Schadendorf D, Hemminki $\mathrm{K}$ and Kumar R. TERT promoter mutations in bladder cancer affect patient survival and disease recurrence through modification by a common polymorphism. Proc Natl Acad Sci U S A. 2013; 110:17426-17431.

41. McKenna A, Hanna M, Banks E, Sivachenko A, Cibulskis K, Kernytsky A, Garimella K, Altshuler D, Gabriel S, Daly $\mathrm{M}$ and DePristo MA. The Genome Analysis Toolkit: a MapReduce framework for analyzing next-generation DNA sequencing data. Genome Res. 2010; 20:1297-1303.

42. Li H and Durbin R. Fast and accurate long-read alignment with Burrows-Wheeler transform. Bioinformatics. 2010; 26:589-595.

43. Cibulskis K, Lawrence MS, Carter SL, Sivachenko A, Jaffe D, Sougnez C, Gabriel S, Meyerson M, Lander ES and Getz G. Sensitive detection of somatic point mutations in impure and heterogeneous cancer samples. Nat Biotechnol. 2013; 31:213-219.

44. Robinson JT, Thorvaldsdottir H, Winckler W, Guttman M, Lander ES, Getz G and Mesirov JP. Integrative genomics viewer. Nature biotechnology. 2011; 29:24-26.

45. Wang K, Li M and Hakonarson H. ANNOVAR: functional annotation of genetic variants from high-throughput sequencing data. Nucleic Acids Res. 2010; 38:e164.

46. Abecasis GR, Altshuler D, Auton A, Brooks LD, Durbin RM, Gibbs RA, Hurles ME and McVean GA. A map of human genome variation from population-scale sequencing. Nature. 2010; 467:1061-1073.

47. Wang J, Zhuang J, Iyer S, Lin XY, Greven MC, Kim BH, Moore J, Pierce BG, Dong X, Virgil D, Birney E, Hung
JH and Weng Z. Factorbook.org: a Wiki-based database for transcription factor-binding data generated by the ENCODE consortium. Nucleic acids research. 2013; 41:D171-176. 